\title{
A CONTEXTUALIZAÇÃO DO ENSINO SUPERIOR EM SANTARÉM-PARÁ
}

\section{A BACKGROUND OF HIGHER EDUCATION IN SANTARÉM - PA}

Ednea do Nascimento Carvalho

Universidade Federal do Oeste do Pará (UFOPA), Santarém, PA, Brasil, edneancar@yahoo.com.br

\begin{abstract}
RESUMO
Discute-se o ensino superior no município de Santarém a partir do contexto público e privado, com ênfase na criação da UFOPA e sua representatividade para a região Oeste do Pará, agregando a incorporação de formação territorial e difusão espacial, ou seja, como os arranjos espaciais dinamizados por mais este agente, o educacional, determinam novas práticas espaciais e culturais. Com o intuito de responder a esta indagação buscou-se metodologicamente o aporte etnográfico que inclina-se a interpretar o microssocial, e para isso, utiliza-se de uma lente de aumento. Para fazê-lo aplica métodos e técnicas que compatibilizam com a abordagem qualitativa, que o torna descritivo por excelência. Como resultados apontam-se o aumento do número de construções como: quitinetes, lanchonetes, bares universitários, livrarias, além de eventos para o publico universitário, denotando a intricada rede de relações socioculturais que vai tecendo o espaço urbano santareno.
\end{abstract}

Palavras-chave: Difusão espacial. Praticas espaciais. Relações socioculturais. Ensino Superior. Santarém. Espaço urbano.

\begin{abstract}
It discusses higher education in the city of Santarém from the public and private context. With emphasis on the creation of UFOPA and their representation to the western region of Pará, adding the incorporation of territorial training and special broadcast, that is, as the special arrangements for more streamlined this agent, educational, determine new special and cultural practices. In order to answer this question we sought to methodologically ethnographic contribution leaning to interpret the microsocial, and for that, we use a magnifying glass. To do it, apply methods and techniques that harmonize with the qualitative approach that makes descriptive par excellence. The results points to the increased number of buildings as kitnetes, cafeterias, university bars, bookshops, as well as events for college students, showing the intricate network of social and cultural relations that weaves the urban space of Santarém.
\end{abstract}

Keywords: Special broadcast. Special practices. Socio-cultural relations. Higher education. Santarém. Urban space.

Artigo recebido para publicação em outubro de 2014

Artigo aceito para publicação em março de 2015

\section{INTRODUÇÃO}

A Amazônia, desde o seu povoamento, iniciado nos séculos XVII e XVIII, passou e vem passando por inúmeras formas de ocupação, seja política ou econômica (ESTEVES, 1993). Ressalta-se que nos anos de 1960 e 1970 a ocupação territorial da região Amazônica esteve impulsionada pelos Planos de Desenvolvimento da Amazônia e de Desenvolvimento Nacional, os chamados PNDAS e PNDS, que tratavam o desenvolvimento a partir do expansionismo do capital e vinculavam-se à ideologia da ditadura militar. "A ditadura militar adotou, sobretudo duas orientações básicas: uma de geopolítica de 
segurança nacional e outra de caráter econômico, visando implantar na região o capitalismo extensivo". (IANNI, 1992. p.132).

Um fator locacional que merece destaque na apresentação desta discussão é a abertura da BR 163 ligando Cuiabá, capital do Mato Grosso, a Santarém, Pará, representando, assim, a integração do território brasileiro a partir das políticas desenvolvimentistas propostas pelo governo militar. Contudo, destaca-se aqui que, de toda a sua extensão, a rodovia no estado do Pará tem em torno de quarenta por cento sem nenhuma pavimentação e alguns pequenos trechos em obras; no Estado do Mato Grosso encontra-se totalmente pavimentada. (CASTRO, 2009.).

Por conta da intensificação dos projetos de colonização e diversos financiamentos que geraram vários tipos de empreendimentos, sobretudo os agropecuários, incentivou-se a vinda de colonos do Sul que se fixaram ao longo da rodovia e, depois de alguns anos, começaram a cobrar políticas públicas, sobretudo educacionais, que favorecessem a permanência da população jovem na região.

As políticas educacionais públicas e privadas se cristalizam em ações espaciais, a partir da instalação de instituições educacionais. Geralmente, o processo se dá de forma concentrada, várias instituições educacionais de esferas públicas diferenciadas e outras privadas se instalam em cidades que concentram, ou melhor, recebem investimentos econômicos, tornando-se centros de uma região.

Se de um lado há a concentração de comércio, bens e serviços, há, também, uma área de influência e, portanto, de dependência dos municípios vizinhos em relação ao centro mais dinâmico. Esta dispersão a partir do centro é percebida pelos "fixos" e "fluxos", viabilizando a continuidade do processo (VASCONCELOS JUNIOR, 2006).

Os arranjos espaciais dinamizados por mais este agente, o educacional, determinam novas práticas espaciais e culturais, facilmente perceptíveis no cotidiano dessas cidades. O número de construções de habitações simples como quitinetes, lan houses, lanchonetes, bares universitários, livrarias e 
papelarias, além de eventos para o público universitário, denotam a intricada rede de relações socioculturais que se vai tecendo nestes lugares.

\section{O ensino superior em Santarém: o público e o privado}

O resgate do papel do Estado se apresenta a partir da remissão da regionalização e da região, justificando, assim, a recuperação da atuação do Estado no que diz respeito aos serviços prestado pelo mesmo, pois, na tentativa de configurar essa atuação, considera-se, automaticamente, que a região esteja no bojo do resgate. Tal fato ocorre porque a região, sendo isso mais importante, como aspectos espaciais e territoriais, se apresenta materialmente como parte do Estado-Nação, composto pela apropriação de partes do espaço por conta das disposições individualizadas por atores sociais locais, que delineiam a conjuntura social das regiões (BECKER, 2008).

A referência que se tem quanto a essa discussão é que "as regiões são constituídas por arranjos de frações de classes não monopolistas e adquirem certa identidade do ponto de vista da estrutura econômica, do ponto de vista cultural, do ponto de vista político" (DULONG, 1977, p.23), ou seja, as regiões têm objetivos políticos próprios, derivam do próprio Estado, que não é abstrato, e, sendo parte do mesmo como manifestações espaciais de vantagens políticas específicas, as regiões dialogam com o Estado no intuito de pressionar, relativizar o poder homogêneo e dominante do Estado, conferindo-lhe autenticidade de um papel fundamental. (BECKER, 2008).

Consequentemente, as regiões podem resultar de um relacionamento dialético entre as ambições tecnocráticas e práticas do poder; não obstante, do outro lado estão as práticas sociais, demandas e processos coletivos, portanto é nesse cenário que se configuram e se formam as regiões, sendo legitimadas pelo Estado.

Em outros lugares, em outros momentos, é o Estado que atua primeiro, e depois se forja a região: os interesses políticos dos quais a região é uma expressão digerem a decisão tecnocrática e dão margem ao surgimento das sociedades locais que se apropriam da região. As sociedades locais relativizam o papel das decisões tecnocráticas do poder. O Estado tem que dialogar com suas regiões, com os interesses políticos específicos especializados e regionalizados, que são ele 
mesmo, em última análise, e negociar formas diferenciadas para poder agir. (BECKER, 2008, p. $15)$.

Considera-se, portanto, que seja essa a resposta da retomada da regionalização e da região. Analisando, do ponto de vista teórico, como o resgate do papel do Estado funciona, na prática interfere diretamente na dinâmica espacial, constituindo e fortalecendo, também, a aparição das "ilhas dinâmicas na periferia" (BECKER, 2008, p. 15).

Mediante a política desenvolvimentista, ou melhor dizendo, a chamada "Política Nacional de Desenvolvimento Regional” (BECKER, 2008, p.15), desenvolvida pelo Ministério das Cidades, antes chamado da Integração, torna-se relevante apontar que os projetos desenvolvimentistas pensados se instituem apenas pelo viés político, menosprezando o social, ambiental e cultural porque estão inseridos em um megaprojeto de política nacional que determina as diretrizes de atuação dos subprojetos.

Caracterizando a discussão no âmbito da região Amazônica, temos uma interposição do Estado de maneira autoritária, partindo do pressuposto tecnocrático que fundamentou e justificou a criação das regiões. Um exemplo nítido refere-se à criação da Amazônia Legal, amparada por uma ação geopolítica do Governo Federal, argumentando a necessidade de desenvolvimento regional; contudo implicitamente o projeto tinha a finalidade de implementar o controle territorial de uma região que possui inúmeros recursos naturais.

\footnotetext{
As rodovias implementadas no período Kubitscheck, 1958-60 foram elementos espaciais fundamentais no recontorno da região, como se foram duas grandes pinças em torno da Hileia: a Belém-Brasília e a Brasília-Cuiabá-Porto Velho-Rio Branco. Estas rodovias, como é notório, foram fundamentadas no processo de ocupação da região e formação da fronteira econômica e demográfica nacional ao longo desse grande arco em torno da Hileia. Mas, foi com o Programa de Integração Nacional de 1970 que, o Estado passou a tomar conta, controlar e ocupar a região. (BECKER, 2008, p.16).
}

É perceptível como o Estado se impôs e consolidou suas ações geopolíticas para o controle de uma determinada região, mas é recorrente salientar de que maneira ocorreu essa imposição, dada a sistematização dos atos programados para a consolidação proposital do projeto. Assim, a ferramenta usada foi à implantação de redes por meio de uma malha programada que desempenharam um papel 
estratégico na conexão interdependente da região, apesar de a mesma, ainda, se manter visivelmente desarticulada.

Há, assim, novos atores com novas estratégias, como a Amazônia foi mudando, como foi reconstruída, inicialmente através da intervenção do Estado e, a seguir, das relações que se estabeleceram com as populações regionais. Essa combinação de ações resultou em uma nova geografia amazônica, que exige novas escalas de ação e uma nova política regional. Pois aquelas áreas que foram criadas devido às intervenções do Estado, os pólos, os projetos de colonização da União, os projetos do governo federal em Rondônia e na Transamazônica, geraram subregiões e uma malha sócio-política. (BECKER, 2008, p.19).

A partir da discussão estabelecida por Becker, presenciam-se mudanças na região Amazônica, sobretudo no Oeste do Pará (figura 1) em destaque, que se apresenta atualmente com uma rica diversidade regional, novos atores, demandas, interesses novos que se interligam por meio das complexidades que se materializam. Contudo, é necessário dizer que cabe ao Estado fazer o reconhecimento das complexidades e especificidades locais, com o comprometimento de contribuir para a qualificação e o desenvolvimento da região no que se refere à amplitude de um projeto nacional, ou seja, "todas as categorias de atores sociais, sem exceção apontaram como medida mais importante para solucionar conflitos e promover o desenvolvimento, a presença do Estado" (BECKER, 2008, p.19). 


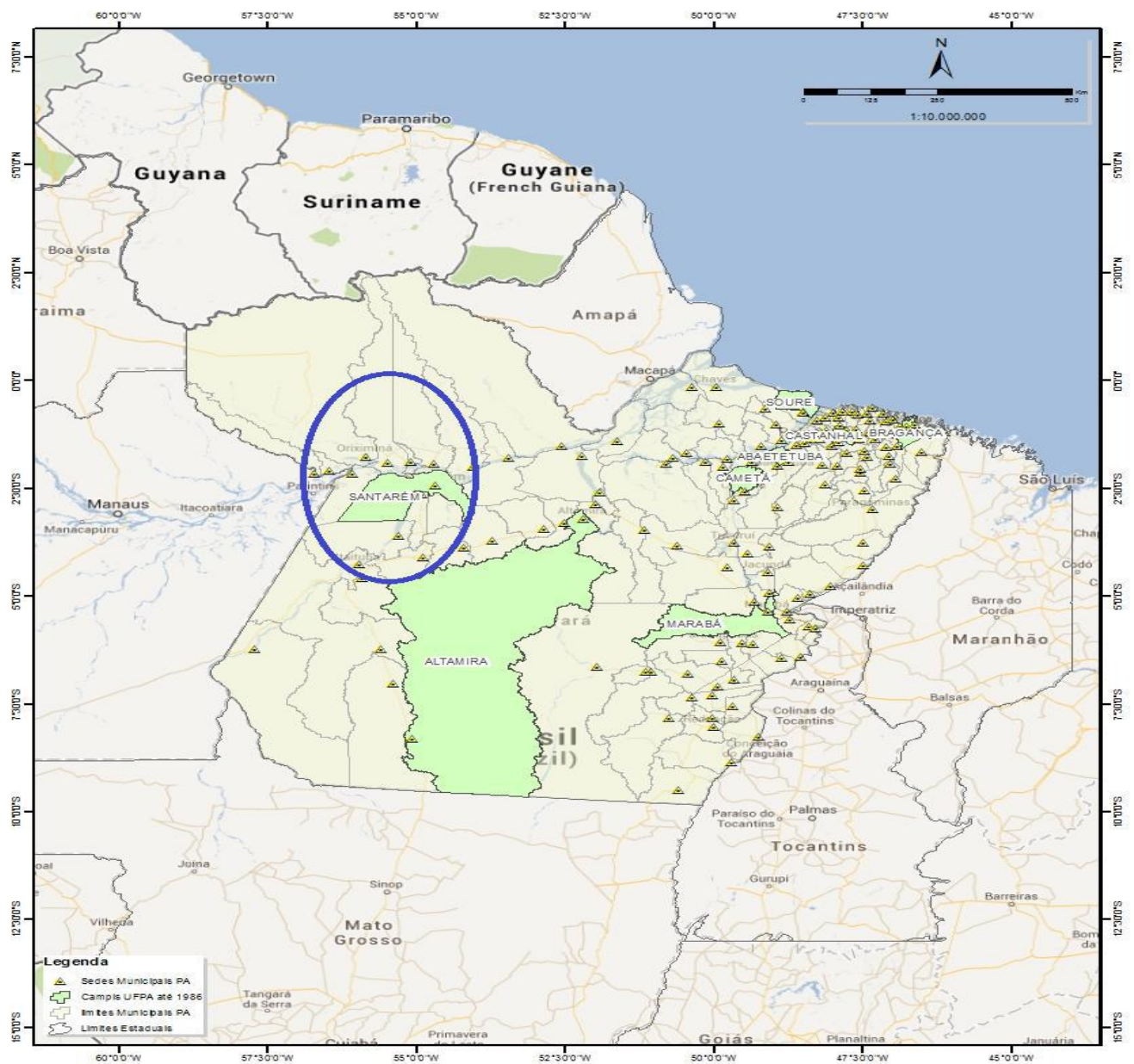

Figura 1. Localização da Região Oeste do Pará e do município de Santarém.

Fonte: Base Cartográfica do Ibama/2013. Elaboração: Gobolovante, R. F.

Portanto, as reflexões apresentadas caracterizam as dimensões espaciais, sobretudo diante dos agentes exógenos, o que evidencia a forma mercantilista dos recursos naturais da região, provocando e acentuando a dicotomia entre os segmentos sociais, culturais e econômicos provocados pelo uso político do território. 0 que provoca a refletir do quanto era o interesse em não dividir o estado paraense em três novos Estados da federação, nitidamente presenciado pelo resultado do plebiscito ocorrido em 2011, quando todos os eleitores participaram e não somente a parte interessada, culminando pela manutenção da unificação territorial do Pará.

O interesse pelo urbano que se tornou emblemático foi o da fronteira, o urbano do planejamento estatal, com suas agrovilas que se tornaram cidades, ou dos acampamentos de estradas de rodagem e de ferro, de grandes projetos, de garimpo e mineração, que constituíram povoados e depois sedes municipais; mesmo aquelas cidades já existentes em áreas de fronteira e incorporada como pontos estratégicos nos planos governamentais como Santarém, Altamira e Marabá. (CASTRO, 2009, p.36). 
Essa discussão tem como exemplo a implantação da educação superior, seja ela privada ou pública. Em Santarém é possível presenciar várias mudanças que se acentuaram por conta da implantação da Universidade Federal do Oeste do Pará.

É válido destacar que, anteriormente ao projeto da UFOPA, existiam no município faculdades de origem privada: Centro Universitário Luterano de Santarém/ Universidade Luterana do BrasilCEULS/ULBRA, Faculdades Integradas do Tapajós-FIT e Instituto Esperança de Ensino SuperiorIESPES, subsidiadas por associações mantenedoras que conduziam o ensino superior apenas no viés do ensino, indiferentes à pesquisa e extensão. Tais faculdades implantaram cursos que são considerados básicos quanto à instalação de serviços essenciais à população, como: enfermagem e formação de professores, por conta da demanda das prefeituras circunvizinhas; e direito e administração em gestão pública, com a intenção de atender às secretarias estaduais e municipais. Cursos esses ofertados na modalidade presencial com aulas todos os dias; e a distancia (EAD), cujas turmas tinham aula somente no período de férias escolares e ou uma vez por semana.

A lacuna deixada pelo Estado durante vários anos permitiu que o ensino superior privado se consolidasse e, assim, assumisse o controle e se deleitasse no contexto educacional desse nível de ensino. Isso ocorreu por conta de que a década de 1980, conhecida como "década perdida", em função da baixa credibilidade das instituições públicas no âmbito governamental municipal, estadual e federal, acentuou, ainda mais, as diferenças sociais, econômicas, culturais e principalmente, educacionais.

Posteriormente aos anos de 1980, mesmo com a chegada dos campi da UFPA a Santarém, Altamira e Marabá, as condições educacionais pouco se alteraram; isso se deve ao fato de que a inexpressividade dos cursos superiores públicos era visível, enquanto que o ensino privado, em função das políticas educacionais adotadas pelo Estado-Nação, se fortalecia e oferecia a única opção de qualificação para a população que não podia se ausentar das regiões interioranas para as capitais, Belém ou Manaus, a fim de se qualificar nas mais variada áreas do conhecimento.

Some-se a ele a dispersão da população, a implantação tardia da educação básica na região, do que resultou uma rede reduzida de escolas para atender uma clientela que, em algumas décadas, 
tornou-se desproporcionalmente maior que sua capacidade; a inferioridade técnica e arquitetônica das infraestruturas escolares; a fragilidade delas devido ao clima equatorial super úmido, a carência e a necessidade de um programa de transporte escolar que se coadune com as especificidades regionais. (LOUREIRO, 2013, p. 172).

O que sustenta esta discussão é que, de modo geral, todos esses apontamentos feitos são conhecidos contudo, as políticas educacionais pensadas e programadas para eliminá-los ou minimizá-los, a médio e curto prazo, não obtiveram resultado imediato, tornando-os parte do cotidiano escolar.

A combinação desses elementos na educação básica, juntamente com fatores endógenos à região, irá refletir na apropriação do ensino superior pela população local. Claramente, enquanto o ensino superior público formava professores para atuar no campo da educação básica, tendo uma média de 300 alunos por semestre letivo, o ensino superior privado, com um público em torno de 500 a 800 alunos/semestre letivo, formava administradores, veterinários, advogados, economistas, que por conta do desempenho na instituição enquanto alunos transformavam-se em posteriores professores, absorvidos pelas próprias instituições, o que criava um círculo vicioso, colaborando com a política de privatização do ensino superior no Brasil.

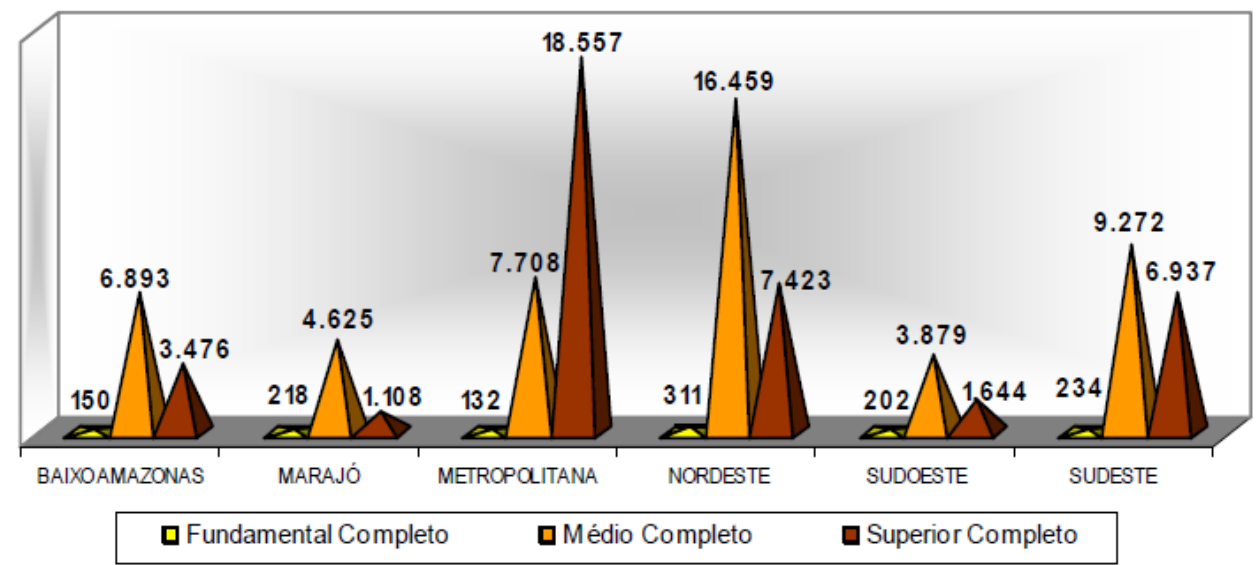

Figura 2. Formação dos docentes da educação básica nas Mesorregiões paraenses. Fonte: Projeção do PROPLAN/UFPA com base em informações do MEC/INEP, 2005.

A figura 2 nos apresenta a carência do ensino superior público no interior do Estado Paraense, de acordo com dados de 2005 fornecidos pelo MEC/INEP. Mas a realidade pouco mudou: apesar da 
implantação de uma instituição de ensino superior (IES), as condições que se apresentam na consolidação do ensino superior público são fragilizadas. (Tabela 1)

\begin{tabular}{lccccc}
\hline Local & Creche & Pré-Escola & $\begin{array}{c}\text { E.F/Séries } \\
\text { Iniciais }\end{array}$ & $\begin{array}{c}\text { E.F/Séries } \\
\text { Finais }\end{array}$ & Ensino Médio \\
\hline Brasil & 48,5 & 51,8 & 62,4 & 79,2 & 91 \\
Região & 34,4 & 34,3 & 46,6 & 61,6 & 92,6 \\
Norte & 20,5 & 24,4 & 35,5 & 51,9 & 94,8 \\
Pará & & & & & \\
\hline
\end{tabular}

Tabela 1. Docentes com curso superior lotados em diversos níveis de ensino - Brasil/região Norte/Pará - 2011 (\%). Fonte: MEC/Secretaria do ensino superior/2011.

Essa tabela nos apresenta a realidade atual de como o ensino superior se reflete na educação básica; o que esta tabela não nos apresenta é que, para alcançar tais números, o ensino superior privado foi o condutor do processo, pois diversos são os desafios na formação docente, contudo, manter-se atualizado é um dos maiores. E visando este mercado, as empresas privadas de ensino superior se espalharam porque o público se manteve ausente neste processo.

Além do mais, existe uma brecha não preenchida de qualificação quanto às demais áreas do conhecimento, sobretudo nas ciências exatas e biomédicas, o que foi utilizado pelas instituições superiores privadas de Santarém, que investiram criando e mantendo cursos nestas áreas sem nenhuma concorrência.

Ao considerar o imaginário político e territorial no processo de articulação, apoiado em uma discussão que descende da aceitação mínima da política como uma maneira de controle do sentimento humano e do território como base para o convívio diário, promove-se o imaginário social, que se torna o condutor para as interpretações do simbolismo visíveis nas relações dos homens com o meio, materializando-se nos mais diversos modos de organização socioespacial. Mantendo-se essa linha de raciocínio, é possível afirmar que o "imaginário político, território e natureza encontram-se entrelaçados em situações concretas, explicando algumas das questões chave, tanto da representação territorial da política como o sentido dos discursos e das bandeiras regionalistas" (CASTRO, 2008, p. 155).

Pensar o valor simbólico dos objetos geográficos e de suas relevâncias nas representações sociais, haja vista que o entendimento essencial de um imaginário geográfico inserido no político, então: “a 
correspondência entre a natureza e o discurso político, fundado no imaginário social sobre ela; 0 regionalismo, apoiado em um nós coletivo de base territorial e a representação política territorial, que realiza a prática política com suporte no imaginário geográfico" (CASTRO, 2008, p. 179).

O planejamento do processo de interiorização da UFPA exemplifica tal discussão, a ponto de expor os objetivos e as possibilidades pelos quais se basearam a incorporação e a legitimação na organização territorial, inserindo os atores sociais, suas relações e seu modo de vida no sentido de consolidação do projeto.

Os cursos foram planejados para serem ministrados no período intervalar das aulas da UFPA e das redes de ensino, de forma concentrada, com docentes da capital que se deslocariam para os polos do projeto, onde a UFPA, criaria campi. A opção de interiorizar foi uma opção política dentro do contexto da época e tinha como objetivo principal tornar a UFPA efetivamente uma universidade do estado. A interiorização fez com que a UFPA se repensasse e, vinte e cinco anos depois, é uma universidade multicampi. (FONTES, 2012, p. 99).

Ao delineamento proposto cabe discutir que o imaginário político de base territorial coordena a relação entre "a dimensão do território e as possibilidades para um processo civilizatório de democracia, oportunidades e justiça”, (CASTRO, 2008, p. 183), permitindo caracterizar que o processo de escolha dos cursos, a forma como eram ministrados, a infraestrutura dos campi e as características das turmas não dispunham de uma importância mais contextualizada no cenário educacional de interiorização, ou seja, o fator determinante seria a combinação política e uso do território como principal duto condutor das ações geopolíticas.

O projeto de interiorização, logo no início, apresentou problemas graves e que deveriam ser solucionados em curto prazo, que era o caso dos laboratórios para atender as licenciaturas, sobretudo as exatas e naturais.

$\mathrm{Na}$ tentativa de minimizar o descontentamento geral e continuar o projeto de interiorização, o Conselho de Ensino e Pesquisa (CONSEP, 1986), opta pelas licenciaturas em Letras, Pedagogia, Matemática, Historia e Geografia, ficando determinado que, mesmo com a autorização de instalação dos cursos, deveriam ser efetivadas por meio de "avaliações qualitativas e periódicas, as quais devem ficar disponíveis ao conhecimento tanto da comunidade quanto dos conselhos" (CONSEP, 1986). 
O professor Mario Cardoso, presidente da ADUFPA em 1988, ressalta a preocupação com a qualidade dos cursos que serão oferecidos no interior, haja vista que em anos anteriores haviam ocorrido situações bastante preocupantes quando se realizava cursos fora da sede.

Em seu planejamento institucional, a UFPA previa inicialmente ao programa de interiorização oito polos regionais, estrategicamente escolhidos por conta de: a) localização geográfica, b) facilidade de deslocamento, c) importância econômica, d) polo de desenvolvimento regional. Mas para que o projeto realmente ocorresse, era necessária a parceria entre Estado, Prefeituras e Universidade. Entretanto, o Estado e o próprio Ministério da Educação eximiram-se do apoio financeiro de que o projeto tanto necessitava, ficando as prefeituras municipais como subsidiárias financeiras do projeto.

A necessidade de recursos financeiros, no primeiro momento, representou o principal obstáculo a ser superado no projeto de interiorização. Então era preciso repensar a utilização dos recursos: "o professor Seixas Lourenço ressalta que, para conduzir essa situação, foi muito importante a autonomia que a UFPA possuía para administrar seus recursos" (FONTES, 2012, p. 101).

A partir do momento em que o poder local assumia, junto à UFPA, o projeto de interiorização, imediatamente se assinavam convênios para que no semestre seguinte começasse a funcionar o polo de ensino superior naquela localidade. A saída foi estabelecer convênios nos quais as prefeituras cederiam salas, alojamentos de professores e alimentação, garantindo, assim, a contrapartida para que a interiorização fosse bem sucedida.

Mas nem todas as prefeituras tinham interesse de instalar o ensino superior público nos municípios, e, portanto dificultavam a contextualização do processo de interiorização, como relembra a professora Hildete Pereira, que morava em Xinguara e estudava Pedagogia em Marabá: "os alunos oriundos de Xinguara não tiveram apoio financeiro algum", e rememora que "não era interesse algum das prefeituras ter gente na Universidade, havia uma crença de que formavam comunistas, formavam marxistas, chegando ao ponto de na etapa seguinte não termos um real para comer". 
Quando havia apoio das prefeituras, o mesmo estava condicionado ao não abandono do curso. Havia uma fiscalização por parte do prefeito e do secretário municipal de educação, no sentido de saber quais eram os alunos que mais faltavam, aqueles que haviam deixado o curso e até mesmo aqueles que reprovavam nas disciplinas oferecidas em etapas anteriores (FONTES 2012).

Em relação à saída dos professores para o interior, existia uma preocupação muito grande quanto a regulamentação da ida dos mesmos para a interiorização. Tal preocupação tinha como fundamento regularizar e viabilizar a saída dos professores de maneira organizada e sistematizada para que não ocorram privilégios e/ou prejuízo para a sede, ou seja, o professor que se dispusesse a ir para o interior deveria cumprir seu Plano Individual de Trabalho (PIT) em parte ou total na capital, pois receberia diárias e passagens para cumprir suas atividades no interior, o que não justificaria colocar isso no seu PIT. Quanto a isso, a professora Maria Celeste Medeiros aponta o debate várias vezes nas reuniões do CONSEP, quando: "para de fato organizar melhor esse período de interiorização", que também é uma preocupação do conselheiro Netuno Nobre Villa: "é fundamental que toda a atividade conste do plano departamental porque senão daqui a pouco todo mundo vai querer ir para o interior, pega um salário aqui e outro lá, isso é tremendamente perigoso".

Após a regulamentação do processo de saída dos professores pelo CONSEP, a UFPA fortaleceu suas atividades nos campi de Santarém, Altamira e Marabá, ampliando-as para Cametá, Abaetetuba, Soure, Bragança, Castanhal, gradativamente, e definindo a atuação dos docentes na interiorização.

Finalmente o primeiro passo do processo de interiorização havia-se consolidado, mesmo tendo obstáculos e críticas pedagógicas quanto à forma por que seriam ministrados os cursos. Contudo, era essencial pensar nas etapas seguintes. E o passo mais importante seria fixar os docentes nos campi do interior para que os cursos deixassem de ser exclusivamente intervalares, passando também a regulares, ou seja, era necessário um corpo docente fixo que constituísse um processo sequencial de funcionamento dos campi com quatro períodos regulares de aulas, caracterizando definitivamente a identidade de uma universidade brasileira autenticamente multicampi. 
A descentralização do ensino superior no estado do Pará perpassa pela própria história da UFPA, e seu projeto de interiorização do ensino superior, até a consolidação do mesmo, tem o campus universitário de Santarém como a primeira iniciativa de implantação de uma instituição de ensino superior no Oeste Paraense. Entretanto, a história do ensino superior federal em Santarém teve seu início muito antes, com a implantação do Curso de Pedagogia, ocorrida em 14 de outubro de 1970, por meio do Parecer nº 663/1970 do Conselho Federal de Educação (CFE) e da Resolução n 39/1970 do Conselho Superior de Ensino e Pesquisa (CONSEP), com a instituição dos Núcleos de Educação da UFPA.

Mas é preciso salientar que o principal objetivo desse convênio firmado com o Departamento de Ensino do Ministério da Educação e Cultura - MEC, para realização de cursos especiais de qualificação e habilitação de professores em atuação no interior do estado, estaria ligado diretamente à ocupação do território brasileiro, por conta das políticas públicas destinadas ao "desenvolvimento" da região Amazônica.

\footnotetext{
A outra política importante desse Programa de Integração Nacional foi a superposição de territórios federais sobre territórios estaduais, como os pólos de desenvolvimento que marcaram a Amazônia: o Pólo Amazônia, implantado a partir de 1974; a incorporação em 1977 do recém criado estado do Mato Grosso do Sul, ampliando a escala da Amazônia Legal; o Programa Grande Carajás e outros de exploração mineral; o Projeto Calha Norte. Grandes projetos e programas que asseguravam a presença da União na região, e que aí deixaram marcas profundas (BECKER, 2008, p.17).
}

Portanto, o Núcleo de Educação de Santarém, implantado pela UFPA juntamente com o de Macapá, em 14 de outubro de 1970, para realização do Curso de Licenciatura Polivalente de $1^{\circ}$ Ciclo, representava uma ação geopolítica de controle da região. Dando continuidade a esse projeto de Geografia Política para a região, sob a orientação do Parecer Federal nº 251/1962, foi criada a primeira turma de licenciatura curta com habilitação em Administração Escolar, no período de 1971 a 1973, em etapas ofertadas nos períodos de férias, com o objetivo de preparar profissionais não docentes do setor educacional, bem como professores das escolas normais. Nesse período as primeiras turmas funcionaram no Colégio Estadual Álvaro Adolfo da Silveira, segundo os critérios da política nacionalista de "Integrar para não Entregar" pensada pelo governo ditatorial. 
Reporta-se neste momento que esta situação ainda não é considerada interiorização do ensino superior, mas uma tentativa frustrada de qualificação profissional com o objetivo implícito de encontrar os focos de resistência à ditadura militar no interior da região Amazônica, e além do mais condicionar a população amazônida de que aquela forma de governo estaria protegendo o ícone brasileiro, "a floresta tropical".

[...] É sobretudo, um espaço no qual ocorrem rápidas e profundas transformações. E parece lícito considerar, logo de saída, que esse movimento transformador - essa intensa dinâmica regional, diriam alguns - constrói e desconstrói a fronteira, instaura o novo, refunda o préexistente, hibridiza-os e, apesar de ou por isso mesmo, forja o espaço de fronteira e força a sua consolidação, negando-o dialeticamente, ou seja, fazendo com que deixe de ser fronteira, sendo. Assim, quanto a Amazônia, impõe-se a questão de fundo; o que é - como quem indaga o que já não é mais- a fronteira nacional da qual tratamos. (LIMA, 2008, P.103).

A partir dessa perspectiva de (re)delineamento de fronteira, usando, como ferramenta para a instalação de uso político do território, a qualificação profissional por meio do ensino superior, mais uma tentativa é estabelecida: no ano de 1983, a UFPA oferta o Curso de Pedagogia, com habilitação em Magistério, por meio de um convênio com a SUDAM e a Prefeitura Municipal de Santarém. Esta foi considerada a primeira turma regular de um curso de licenciatura plena da UFPA realizado fora da sede. Nessa época, a coordenação do curso ficou sob a responsabilidade da Profa. Rosilda Wanghon, que representou a primeira coordenação dos serviços educacionais ofertados pela UFPA em Santarém, tornando-se a precursora das coordenações que no futuro viriam a compor o Campus de Santarém.

Realidade ou miragem, avanço ou retrocesso, o fato é que o ensino superior público se materializou em uma região na qual sempre se demonstrou uma complexidade ímpar no que se refere a questões políticas, econômicas, culturais, sociais e educacionais, e que progressivamente vai subsumindo o Oeste do Pará no que se refere à educação superior, delineando novas fronteiras, anunciando reordenamentos e reconfigurações sociais e educacionais próprias.

\section{CONSIDERAÇÕES FINAIS}

O entendimento acerca da temática proporcionou um resgate do (re)pensar os desafios iminentes da educação superior no Brasil e seu processo de interiorização, considerando o significado das mudanças no cotidiano dos municípios e as evidências de reordenamento do espaço geográfico dos mesmos, que não se expressam em fatos isolados, mas nas singularidades endógenas, pois são escolhidos para 
abrigar as instituições federais e ou estaduais de formação superior, promovendo o debate quanto às políticas públicas de reestruturação do território.

A manifestação de uma ação geopolítica legitimada por conta de um agente educacional, subsidiado por políticas educacionais voltadas ao interesse dos grupos políticos que delineiam o espaço geográfico brasileiro, nos revela suas tendências e desígnios, antecipando-se a alguns desafios proeminentes que se revelarão na aproximação e interação progressiva entre os desejos da população amazônida e 0 conhecimento científico que estampará por meio das conexões e interdependências, cujas intercessões apresentam-se com intensidade e abrangência.

Por isso, importa que se reflita independentemente das conclusões que poderão vir a configurar o reconhecimento das potencialidades interligadas diretamente à condução de que a universidade realce, por meio de sua origem geográfica, a inspiração neoliberal que constitui as relações de poder e se materializam a partir da complexidade de inextrincáveis teias que desafia as múltiplas diversidades locais e regionais.

\section{REFERÊNCIAS}

BECKER, Bertha K. Uma nova regionalização para pensar o Brasil?. In: LIMOND, Ester.; HAESBAERT, Rogério.; MOREIRA, Ruy. (Orgs). Brasil, século XXI - por uma nova regionalização? Agentes, Processos e Escalas. São Paulo: Max Limonad, 2008.

BRASIL. IBGE. Censo Demográfico: 2010. Educação. Disponível em www.ibge.gov.br. Acesso em 20 de janeiro de 2014.

BRASIL. INEP, MEC. Sinopse Estatística da Educação Superior: censo da educação superior 2010. Brasília: Ministério da Educação e do Desporto: Instituto Nacional de Estudos e Pesquisas Educacionais, 2013. Disponível em www.inep.gov.br. Acesso em 14 de janeiro de 2014.

BRASIL. INEP. Educação Superior Brasileira: o Estado do Pará - 1991-2004. Brasília, DF: Ministério da Educação e do Desporto; Instituto Nacional de Estudos e Pesquisas Educacionais. 2006.

BRASIL. Ministério da Educação. Mec/Secretaria de Ensino Superior. Diretrizes Curriculares Nacionais para a Educação Superior. Brasília: MEC, 2011.

CASTRO, Edna. Processos de trabalho e relações de poder no Carajás. In: D’INCAO, Maria Angela. SILVEIRA, Isolda Maciel da. (Orgs.). A Amazônia e a Crise da Modernização. Belém: 2009. 
DULONG, R. A crise da relação Estado/Sociedade local vista através da política regional. In: POULANTZAS, N. (Org). O Estado em crise. Rio de Janeiro: Graal, 1977.

ESTEVES, Antônio R. A ocupação da Amazônia. São Paulo: Editora brasiliense,1993.

FONTES, Edilza Joana Oliveira. Memória e história da interiorização da UFPA: quando a memória constrói uma história coletiva. Revista Catarinense de História. Florianópolis n.20, p. 93- 114, 2012.

FRANCO, M. S. de C. Homens livres na ordem escravocrata. São Paulo: Ática, 1976.

IANNI, Otávio. A sociedade global. Rio de Janeiro: Civilização Brasileira, 1992.

LIMA, Ivaldo. Escalas Insurgentes na Amazônia Brasileira. In: LIMOND, Ester.; HAESBAERT, Rogério.; MOREIRA, Ruy. (Orgs). Brasil, século XXI - por uma nova regionalização? Agentes, Processos e Escalas. São Paulo: Max Limonad, 2008.

LOUREIRO, Violeta Refkalefsky. Educação Básica como direito humano e capital social: o caso amazônico como retrato da desigualdade. In: ARAUJO, Flavia L. G. M. P. (Org.). Direito Humano: à educação na Amazônia: uma questão de justiça. Sociedade Paraense de Defesa dos Direitos Humanos, Belém, 2013.

Universidade Federal do Pará (UFPA). Plano de desenvolvimento institucional: 2001 a 2010. Belem/PA: EDUFPA.

Universidade Federal do Pará UFPA. Plano de desenvolvimento Institucional: 2005 a 2008. Belém/PA, 2005.

VASCONCELOS JUNIOR, Raimundo Elmo de Paula. O limoeiro da educação: a história da criação da diocese e a ação educacional de Dom Aureliano Matos em Limoeiro do Norte (1938-1968). Tese de doutorado. 2006. 